\title{
WN, Rat Strain
}

National Cancer Institute

\section{Source}

National Cancer Institute. WN, Rat Strain. NCI Thesaurus. Code C14380.

Anterior pituitary tumors nearly $100 \%$ in females over 18 months of age,

pheochromocytomas or preneoplastic nodules in adrenal medulla about $40 \%$ in males, granulocytic leukemia 14\% in animals over 18 months of age. Rarely show hyperplastic cortical nodules or adrenal cortical adenomas. High incidence of severe chronic nephritis. (Snell 1967). High 10-week body weight in males (19/23), and high relative heart weight in 10-week old males (19/23) (Tanase et al 1982). 